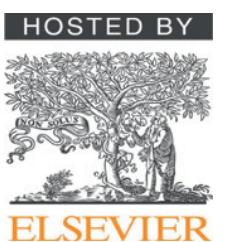

\title{
A case of atrial fibrillation leading to syncope after an electric injury in a patient with twin pregnancy
}

\author{
Oguzhan Celik, Turgut Karabag *, Sait Mesut Dogan, Mustafa Aydin
}

Bulent Ecevit University, Faculty of Medicine, Department of Cardiology, Zonguldak, Turkey

\section{A R T I C L E I N F O}

\section{Article history:}

Received 8 September 2015

Received in revised form 28 October 2015

Accepted 30 October 2015

Available online 6 November 2015

\section{Keywords:}

Electric injury

Atrial fibrillation

Twin pregnancy

\begin{abstract}
A B S T R A C T
The heart is one of the most affected organs during electric injuries. In electrical injuries, mechanical complications such as myocardial rupture, valvular rupture, pericardial effusion as well as a variety of arrhythmias ranging from electrocardiographic changes to ventricular fibrillation may occur. In this paper, we have presented a female patient with twin pregnancy at the 26th week of gestation, in whom syncope due to electric shock occurred and atrial fibrillation was detected on admission to the emergency department and have discussed treatment methods.

(c) 2015 The Society of Cardiovascular Academy. Production and hosting by Elsevier B.V. All rights reserved. This is an open access article under the CC BY-NC-ND license (http://creativecommons.org/licenses/by-nc-nd/4.0/).
\end{abstract}

\section{Introduction}

In modern life, electrical accidents are becoming increasingly more frequent. In individuals exposed to electrical current, a variety of conditions ranging from burn lesions in soft tissues to cardiac complications, neurological damages and even death can occur. ${ }^{1}$ In the present case report we aimed to draw attention to atrial fibrillation with rapid ventricular response in a patient with twin pregnancy at 26th week of gestation, who was admitted to the emergency department with complaints of loss of consciousness and subsequent palpitations.

\section{Case report}

A 26 year old female with twin pregnancy at 26th week of gestation according to the last menstrual period (LMP), was brought to the emergency department with complaints of loss of consciousness due to electric shock. Two hours prior to admission, the patient had been exposed to electrical current passing through the left hand because of touching the light source unit with a wet hand while taking her clothes out of the washing machine. The patient received an electric shock in her left hand and found unconscious by her relatives. On admission to the emergency department, the patient was conscious with ongoing palpitations. The patient had no cardiac risk factors or previous history of cardiac disease. The physical examination revealed that the patient was in good general health condition and conscious, with an arterial blood pressure of $110 / 70 \mathrm{~mm} \mathrm{Hg}$ and an irregular pulse of $134 / \mathrm{min}$. No pathology was detected in other

\footnotetext{
* Corresponding author at: Bulent Ecevit Universitesi Tıp Fakultesi, Kardiyoloji Bolumu, 67600 Kozlu, Zonguldak, Turkey. Tel.: +90 372 2571517; fax: +90 3722577395.

E-mail address: turgutkarabag@yahoo.com (T. Karabag).

Peer review under responsibility of The Society of Cardiovascular Academy.
}

system examinations. Laboratory tests revealed no abnormalities except for anemia (hemoglobin: $8.8 \mathrm{~g} / \mathrm{dl}$ ). Cardiac specific enzymes (CK, CK$\mathrm{MB}$, troponin I) were normal. Thyroid function tests showed no abnormalities. The electrocardiography revealed atrial fibrillation with rapid ventricular response (Fig. 1). Echocardiography revealed no pathology other than minimal tricuspid regurgitation. The patient was administered 21 of $\mathrm{O}_{2}$ per min., fluid infusions $(150 \mathrm{ml} / \mathrm{h})$. Anticoagulation was not considered. The patient was transferred to the intensive care unit and kept under monitoring. $5 \mathrm{mg}$ of metoprolol was administered intravenously within $15 \mathrm{~min}$. The rhythm was converted to sinus rhythm in 5 min after administration (Fig. 2). During her follow-up, no rhythm disturbances were observed. On 24-hour Holter recordings performed the next day, no atrial fibrillation and/or premature beats were detected. The patient was referred for gynecologic consultation and no problems which may threaten the pregnancy were detected. Three days later, the patient was discharged from the hospital without treatment.

\section{Discussion}

Electrocution is an uncommon cause of death and occurs commonly due to the accident. Electricity-caused occupational accidents were determined by certain authors to vary in a wide range from $26.47 \%$ to $81 \%{ }^{2}$ The average age of the victims was 35.25 years with a significant prevalence of the male sex $(74.07 \%)^{2}$

Electrical injuries can cause myocardial or valvular rupture, pericardial effusion, structural changes in coronary arteries whereas life-threatening arrhythmias and electrocardiographic changes such as temporary STsegment elevation and QT prolongation are commonly encountered. ${ }^{3} \mathrm{Ar}-$ rhythmias caused by electrical injury include premature ventricular contractions, atrial tachycardia, sinus tachycardia, atrial fibrillation, ventricular fibrillation, ventricular tachycardia, bundle branch blocks 


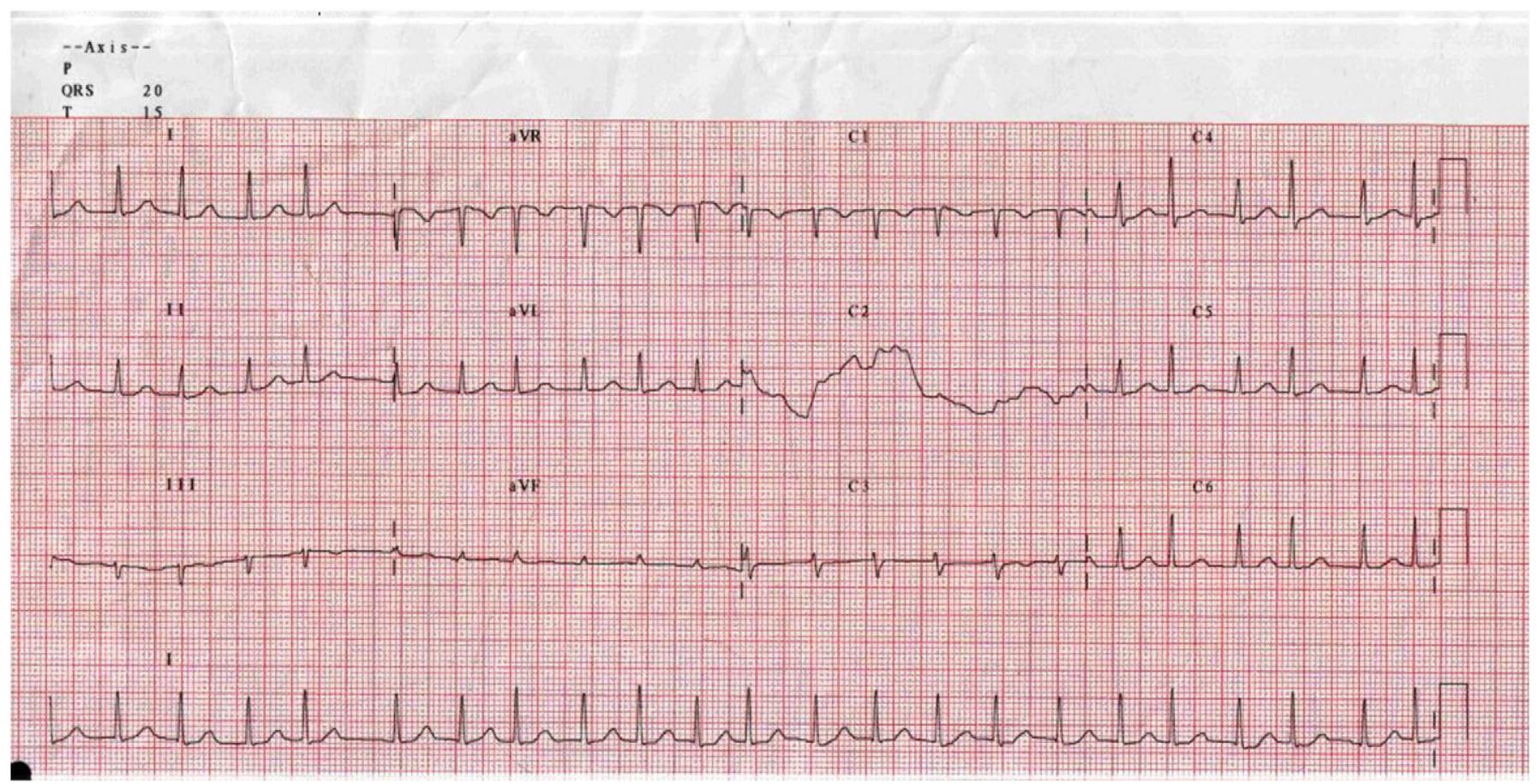

Fig. 1. Electrocardiography showing atrial fibrillation on admission to the hospital.

and complete heart block. ${ }^{4}$ According to a study, the rate of arrhythmia development following electric shock ranges between $10-36 \%$. ${ }^{4,5}$ The electric current mainly affects the sinus node in the conduction system. In addition, it also exerts a direct effect on myocardial cells, leading to minor areas of myocardial necrosis, which may then undergo fibrosis and become arrhythmogenic foci. ${ }^{5}$ The electric current also affects $\mathrm{Na}^{+}-\mathrm{K}^{+}$pump activity, leading to an increase in $\mathrm{K}^{+}$contractions at cellular level, and thus, arrhythmias can be triggered. ${ }^{4}$ However, electric current can cause a change in the myocyte membrane permeability. ${ }^{6}$ In the present case, normal levels of cardiac specific enzymes suggest that atrial fibrillation may have resulted from the fact that sinus node had been affected, rather than because of myocardial damage.

The most common source of published data on accidental maternal electrocution, however, has often been cumulative case reports, which suggest a fetal mortality of $76 \%{ }^{6}$ Fetal injuries have been reported to include sudden deaths, cardiac arrhythmias, intrauterine growth retardation, oligohydramnios, and abortion. ${ }^{7}$ Several parameters have been proposed to influence the seriousness of fetal effects following

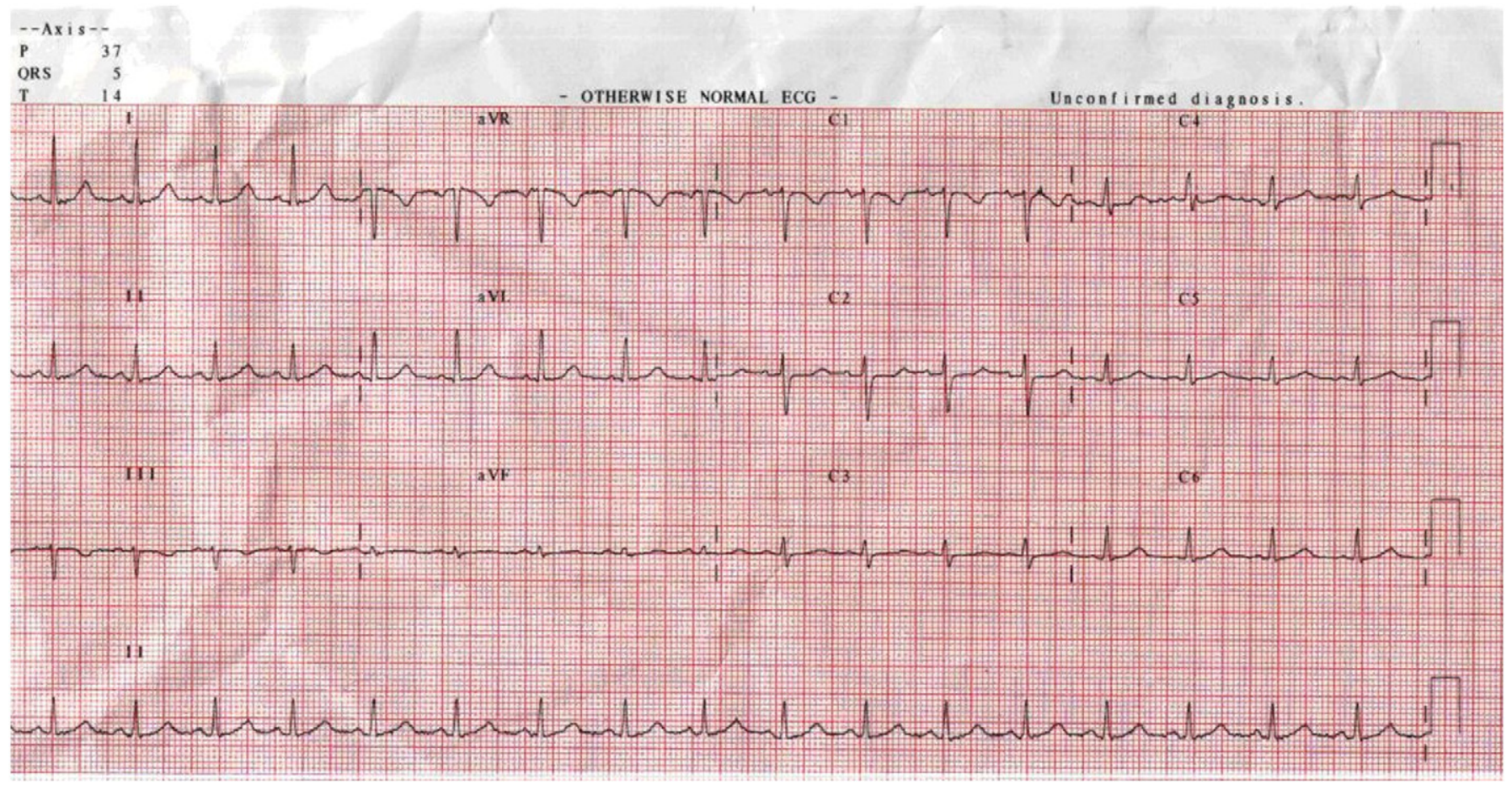

Fig. 2. Electrocardiography showing sinus rhythm after administration of $5 \mathrm{mg}$ metoprolol infusion. 
maternal electric shock. The characteristics of electricity, magnitude of current and the pathway of current flow both appear to be important determinants of fetal risk during accidental maternal electrocution. Besides amniotic fluid transmits current effectively, and this could increase risk of spontaneous abortions and fetal burns or death. ${ }^{7,8}$

Purdue et al., recommend cardiac monitoring for patients with loss of consciousness, recorded arrhythmia, abnormal electrocardiogram on admission and arrhythmia in the emergency department. ${ }^{9}$ In the treatment of atrial fibrillation in pregnancy, the primary aim should be to restore normal sinus rhythm. In the absence of hemodynamic instability, digital, and beta blockers can be used. After irregular heartbeats are controlled with intravenous forms of these drugs, maintenance treatment can be initiated with oral forms of these drugs. However, cardioversion should be considered for the treatment of first choice in cases with hemodynamic instability. Anticoagulants should be used to avoid thromboembolic risk. ${ }^{10}$ Since atrial fibrillation did not last more than $48 \mathrm{~h}$ we did not consider to anticoagulate the patient. Because the patient had normal hemodynamics, we preferred to perform pharmacological cardioversion after monitoring and used beta blockers as the drug of choice. The patient's normal sinus rhythm was restored in a short period of time and oral treatment was not planned because her heart rate was stabilized.

In conclusion, electrical injuries can cause arrhythmias such as temporary atrial fibrillation. The patient should be kept under close monitoring with respect to life-threatening arrhythmias such as syncope.

\section{Funding}

None

\section{Conflict of interest}

No potential conflict of interest relevant to this article was reported.

\section{References}

1. Fish RM. Electrical injury: part I. Treatment priorities, subtle diagnostic factors, and burns. J Emerg Med 1999;17(6):977-983.

2. Dokow M. Electrocution-related mortality: a review of 351 deaths by low-voltage electrical current. Turk J Trauma Emerg Surg 2010;16(2):139-143.

3. Rangaraj R, Moorthy N, Patil SS, Manjunath C. Brugada-type electrocardiographic pattern induced by electrocution. Indian J Electrophysiol Pacing 2009;9(1):56-59.

4. Akdemir R, Gunduz H, Erbilen E, et al. Atrial fibrillation after electrical shock: a case report and review. Emerg Med J 2004;21(6):744-746.

5. Bøggild H, Freund L, Bagger JP. Persistent atrial fibrillation following electrical injury. Occup Med 1995:45(1):49-50.

6. Koumbourlis AC. Electrical injuries. Crit Care Med 2002;30(11 Suppl):S424-S430

7. Awwad J, Hannoun A, Fares F, Ghazeeri G. Accidental electric shock during pregnancy: reflection on a case. AJP Rep 2013;3(2):103-104.

8. Jaffe R, Fejgin M, Ben Aderet N. Fetal death in early pregnancy due to electric current. Acta Obstet Gynecol Scand 1986;65(3):283.

9. Purdue GF, Hunt JL. Electrocardiographic monitoring after electrical injury: necessity or luxury? J Trauma 1986;26(2):166-167.

10. Cacciotti L, Camastra GS, Ansalone G. Atrial fibrillation in a pregnant woman with a normal heart. Intern Emerg Med 2010;5(1):87-88. 